\title{
Effect of three aromatic polycarboxylates on the structural diversities and properties of three new cadmium(II) coordination compounds
}

\author{
HONGYAN LIN*, JIAFENG LIN, JING ZHAO, YUAN TIAN, XIANG WANG and \\ GUOCHENG LIU* \\ Department of Chemistry, Bohai University, Jinzhou 121000, People's Republic of China \\ E-mail: linhongyan_2005@126.com; lgch1004@sina.com
}

MS received 4 September 2017; revised 5 November 2017; accepted 15 November 2017; published online 1 February 2018

\begin{abstract}
Three new cadmium(II) coordination compounds $\left[\mathrm{Cd}_{2}(\mathrm{~L})_{2}(\mathrm{btec})\left(\mathrm{H}_{2} \mathrm{O}\right)_{2}\right] \cdot 3 \mathrm{H}_{2} \mathrm{O}(\mathbf{1}),[\mathrm{Cd}(\mathrm{HL})(\mathrm{btb})]$ (2) and $[\mathrm{Cd}(\mathrm{L})(\mathrm{pda})] \cdot 2 \mathrm{H}_{2} \mathrm{O}(\mathbf{3})$ were prepared by hydrothermal reactions of cadmium(II) chloride with ligands $\mathrm{L}\left(\mathrm{L}=\mathrm{N}, \mathrm{N}^{\prime}\right.$-bis(3-pyridyl)octandiamide) in the presence of different aromatic polycarboxylates $\left(\mathrm{H}_{4}\right.$ btec $=1,2,4,5$-benzenetetracarboxylic acid, $\mathrm{H}_{3}$ btb $=$ 1,3,5-tri(4-carboxylphenyl)benzene, $\mathrm{H}_{2}$ pda $=$ 1,4-phenylenediacetic acid). The structures of compounds $\mathbf{1}-\mathbf{3}$ have been determined by X-ray single crystal diffraction analyses and further characterized by infrared spectroscopy (IR), powder X-ray diffraction (PXRD) and thermogravimetric (TG) analyses. Compound 1 displays a 3D metal-organic framework with $(4,4,4)$ connected $\left\{6^{2} .8^{4}\right\}\left\{6^{3} .8^{3}\right\}\left\{6^{4} .8^{2}\right\}$ topology constructed from $2 \mathrm{D}\left[\mathrm{Cd}_{2}(\mathrm{btec})\right]_{\mathrm{n}}$ layers and $\mu_{2}$-bridging $\mathrm{L}$ ligands. Compound 2 is a $3 \mathrm{D}(3,3)$-connected $\left\{10^{3}\right\}$ topological network based on the $3 \mathrm{D}[\mathrm{Cd}(\mathrm{btb})]_{\mathrm{n}}^{\mathrm{n}-}$ framework and the protonated monodentate HL ligand. Compound 3 shows a 2D layer with $(3,5)$-connected $\left(4^{2} \cdot 6^{7} \cdot 8\right)\left(4^{2} \cdot 6\right)$ topological structure, which are further linked by hydrogen bonding interactions to form a 3D supramolecular network. The influences of three aromatic polycarboxylates on the structures of title compounds are investigated. Further, the fluorescent properties of three cadmium(II) compounds and their fluorescent sensing properties towards small solvent molecules and metal cations have been studied.
\end{abstract}

Keywords. Cadmium(II) compounds; polycarboxylates; crystal structures; fluorescent properties; fluorescence sensing.

\section{Introduction}

Over the past few decades, particular attention has been devoted to the design and construction of metalorganic coordination compounds (MOCCs) in coordination chemistry and crystal engineering field, not only because of their intriguing variety of structures and topologies but also due to their potential applications as functional materials in electrochemistry, catalysis, nonlinear optics, gas separation and luminescence. ${ }^{1-6}$ The self-assembly of transition metal salts with mixed ligands of O-donor polycarboxylates and N-heterocyclic bridging ligands have been employed to construct MOCCs with diverse structures and properties. ${ }^{7-10} \mathrm{In}$

\footnotetext{
*For correspondence
}

the self-assembling process, the connectivity and coordination modes of organic ligands usually govern the final coordination frameworks. ${ }^{11-13}$ Even small structural changes of the organic bridging ligands such as the symmetry, length, flexibility or functional groups can lead to obvious differences in the ultimate framework structures and topological networks. ${ }^{14-16}$

Recently, the flexible bis(pyridyl)-bis(amide) ligands have proven to be wonderful N-heterocyclic bridging ligands for producing novel MOCCs. Based on the flexible bis(pyridyl)-bis(amide) ligands with different - $\left(\mathrm{CH}_{2}\right)_{\mathrm{n}}$ - spacers $(\mathrm{n}=0,1,2, \cdots 10)$ and different aromatic polycarboxylates as the mixed ligands, some MOCCs with diversified topological structures and interesting properties have been obtained. ${ }^{17-25}$ For example, Chen's group and Cao's group have prepared 
three $\mathrm{Zn}(\mathrm{II}) / \mathrm{Cd}(\mathrm{II})$ compounds derived from the mixedligand systems of the flexible bis(pyridyl)-bis(amide) ligands with various $-\left(\mathrm{CH}_{2}\right)_{\mathrm{n}}$ - spacers $(\mathrm{n}=0,4,10)$ and dicarboxylates. ${ }^{17-19}$ Utilizing the mixed ligands of the flexible bis(pyridyl)-bis(amide) ligands with different $-\left(\mathrm{CH}_{2}\right)_{\mathrm{n}}$ - spacers $(\mathrm{n}=0,1,2,4,5,6,8)$ and different dicarboxylates or tricarboxylates, our group has obtained a series of $\mathrm{Cu}(\mathrm{II}) / \mathrm{Co}$ (II) coordination compounds, and all of them exhibit significant photocatalytic activities to degrade some organic dyes. ${ }^{20,21}$ By using the flexible bis(pyridyl)-bis(amide) ligands with - $\left(\mathrm{CH}_{2}\right)_{2}$, our group has synthesized a $2 \mathrm{D}$ layered $\mathrm{Cd}$ (II) compound [Cd(3-bpsa) $\left.)_{0.5}(5-\mathrm{AIP})\left(\mathrm{H}_{2} \mathrm{O}\right)\right] \cdot 2 \mathrm{H}_{2} \mathrm{O}$ (3-bpsa $=\mathrm{N}, \mathrm{N}^{\prime}$-bis(3-pyridyl)succinamide, 5- $\mathrm{H}_{2}$ AIP $=5$-aminoisophthalic acid), which shows fluorescent properties and can photocatalytically degrade the dye methylene blue (MB) under UV irradiation. ${ }^{25}$ However, to our knowledge, systematic investigation of the influence of the different polycarboxylates on the formation of coordination frameworks is still limited, ${ }^{22-24}$ and the reports about the fluorescent sensing properties of the coordination compounds constructed by the mixedligands of the flexible bis(pyridyl)-bis(amide) ligands with aromatic polycarboxylates are rare so far, ${ }^{26,27}$ which prompted us to initiate this study.

In this paper, the flexible bis(pyridyl)-bis(amide) ligand $\mathrm{L}$ (N,N'-bis(3-pyridyl)octandiamide) as the $\mathrm{N}$ heterocyclic bridging ligand was selected based on the following considerations: (i) Its two pyridine moieties can rotate around the amide-bridging groups to meet the requirements of the coordination geometries of metal ions. (ii) It has a flexible $-\left(\mathrm{CH}_{2}\right)_{6^{-}}$skeleton which can form diverse coordination configurations. (iii) It can interact by hydrogen bonding interactions among the amide groups and generate the highdimensional supramolecular networks. Three aromatic polycarboxylates, 1,2,4,5-benzenetetracarboxylic acid ( $\mathrm{H}_{4}$ btec), 1,3,5-tri(4-carboxylphenyl)benzene $\left(\mathrm{H}_{3} \mathrm{btb}\right)$ and 1,4-phenylenediacetic acid $\left(\mathrm{H}_{2}\right.$ pda) were selected as the co-ligand. As a result, three new cadmium coordination compounds, $\left[\mathrm{Cd}_{2}(\mathrm{~L})_{2}(\right.$ btec $\left.)\left(\mathrm{H}_{2} \mathrm{O}\right)_{2}\right] \cdot 3 \mathrm{H}_{2} \mathrm{O}$ (1), $[\mathrm{Cd}(\mathrm{HL})(\mathrm{btb})](\mathbf{2})$ and $[\mathrm{Cd}(\mathrm{L})(\mathrm{pda})] \cdot 2 \mathrm{H}_{2} \mathrm{O}(\mathbf{3})$ have been prepared under the hydrothermal conditions. We focused on investigating the influence of the three polycarboxylates containing various carboxyl groups on the structures of target MOCCs, and discuss the effect of flexible bis(pyridyl)-bis(amide) with various coordination configurations and the three polycarboxylates with different coordination modes on the final networks of the title compounds. The thermal stabilities, fluorescent properties and fluorescent sensing behaviors of the title compounds have also been investigated.

\section{Experimental}

\subsection{Materials and methods}

The N-donor ligand $\mathrm{L}$ was synthesized according to the reported method. ${ }^{28,29}$ Three aromatic polycarboxylates $\mathrm{H}_{4}$ btec, $\mathrm{H}_{3}$ btb and $\mathrm{H}_{2}$ pda were commercially purchased from Aladdin Reagent Company (China) and used without further purification. All other chemical reagents and solvents were obtained from commercial sources without further purification. Elemental analyses $(\mathrm{C}, \mathrm{H}$ and $\mathrm{N})$ were determined on a Perkin-Elmer $240 \mathrm{C}$ elemental analyzer. The IR spectra of three title compounds were performed on a Varian 640 spectrometer in the range of $500-4000 \mathrm{~cm}^{-1}$. Powder Xray diffraction (PXRD) investigations were carried out with an Ultima IV with D/teX Ultra diffractometer at $40 \mathrm{kV}, 40$ $\mathrm{mA}$ with $\mathrm{Cu} \mathrm{K} \alpha(\lambda=1.5406 \AA)$ radiation. Thermogravimetric (TG) data were taken on a Pyris Diamond thermal analyzer at a heating rate of $10{ }^{\circ} \mathrm{C} \mathrm{min}^{-1}$ under $\mathrm{N}_{2}$ atmosphere. Fluorescent spectra were carried out using a Hitachi F-4500 fluorescence/phosphorescence spectrophotometer at room temperature.

\subsection{Preparation of the compounds}

2.2a Synthesis of $\left[\mathrm{Cd}_{2}(\mathrm{~L})_{2}\right.$ (btec $\left.)\left(\mathrm{H}_{2} \mathrm{O}\right)_{2}\right] \cdot 3 \mathrm{H}_{2} \mathrm{O}(\mathbf{1})$ : A mixture of $\mathrm{Cd}\left(\mathrm{NO}_{3}\right)_{2} \cdot 2 \mathrm{H}_{2} \mathrm{O}(0.068 \mathrm{~g}), \mathrm{H}_{4}$ btec $(0.038 \mathrm{~g}), \mathrm{L}$ $(0.035 \mathrm{~g}), \mathrm{H}_{2} \mathrm{O}(10 \mathrm{~mL})$ and $\mathrm{NaOH}(0.016 \mathrm{~g})$ was stirred for $30 \mathrm{~min}$ in air, then the suspension was transferred and sealed in a Teflon lined autoclave, which was heated at $120^{\circ} \mathrm{C}$ and kept for 4 days, then cooled to room temperature leading to the formation of colorless block crystals for compound 1 in $46 \%$ yield based on $\mathrm{Cd}$, and manually pick suitable crystal from the precipitation. Anal. Calcd. for $\mathrm{C}_{46} \mathrm{H}_{56} \mathrm{Cd}_{2} \mathrm{~N}_{8} \mathrm{O}_{17}$ (1217.81): C 45.33, H 4.64, N 9.20\%. Found: C 45.18, H 4.81, N 9.36\%. IR $\left(\mathrm{KBr}, \mathrm{cm}^{-1}\right): 3399$ (s), 2923 (w), 2848 (w), 2360 (w), 1655 (m), 1551 (s), 1495 (m), 1439 (s), 1389 (s), 1322 (w), 1285 (w), $1192(\mathrm{w}), 1136(\mathrm{~s}), 1050(\mathrm{w}), 982(\mathrm{w}), 932(\mathrm{w}), 883(\mathrm{~s})$, $827(\mathrm{~s}), 710(\mathrm{~s}), 605(\mathrm{~m}), 562(\mathrm{w}), 512(\mathrm{~m})$.

2.2b Synthesis of $[C d(H L)(b t b)](2)$ : Colorless strip crystals of $\mathbf{2}$ were prepared in a similar way to that described for 1 except that $\mathrm{H}_{3}$ btb $(0.030 \mathrm{~g})$ was used instead of $\mathrm{H}_{4}$ btec (yield $31 \%$ based on $\mathrm{Cd}$ ), then manually pick suitable crystal from the precipitation. Anal. Calcd. for $\mathrm{C}_{45} \mathrm{H}_{38} \mathrm{CdN}_{4} \mathrm{O}_{8}$ (875.20): C 61.70, H 4.38, N 6.40\%. Found: C 61.82, H 4.29, N 6.31\%. IR (KBr, cm $\left.{ }^{-1}\right): 3478(\mathrm{~m}), 3277(\mathrm{~m}), 3045(\mathrm{w})$, 2851 (w), 2362 (w), 1671 (s), 1559 (s), $1484(\mathrm{~m}), 1428$ (s), 1397 (s), $1328(\mathrm{~m}), 1290(\mathrm{~m}), 1203(\mathrm{~m}), 1140(\mathrm{w}), 1046(\mathrm{w})$, $939(\mathrm{~m}), 808(\mathrm{~s}), 732(\mathrm{~s}), 701(\mathrm{~m}), 626(\mathrm{~s}), 563(\mathrm{~m})$.

2.2c Synthesis of $[\mathrm{Cd}(\mathrm{L})(\mathrm{pda})] \cdot 2 \mathrm{H}_{2} \mathrm{O}(3)$ : Colorless block crystals of $\mathbf{3}$ were prepared in a similar way to that described for 1 except that $\mathrm{H}_{2}$ pda $(0.038 \mathrm{~g})$ was used instead of $\mathrm{H}_{4}$ btec (yield $35 \%$ based on $\mathrm{Cd}$ ). The suitable crystal of $\mathbf{3}$ for single X-ray diffraction were obtained by mechanical separation from the precipitation. Anal. Calcd. for 
Table 1. Crystal data and structure refinement for compounds 1-3.

\begin{tabular}{|c|c|c|c|}
\hline Compounds & 1 & 2 & 3 \\
\hline Formula & $\mathrm{C}_{46} \mathrm{H}_{56} \mathrm{Cd}_{2} \mathrm{~N}_{8} \mathrm{O}_{17}$ & $\mathrm{C}_{45} \mathrm{H}_{38} \mathrm{CdN}_{4} \mathrm{O}_{8}$ & $\mathrm{C}_{28} \mathrm{H}_{34} \mathrm{CdN}_{4} \mathrm{O}_{8}$ \\
\hline Formula wt. & 1217.81 & 875.20 & 667.00 \\
\hline Cryst. syst & Monoclinic & Monoclinic & Triclinic \\
\hline Formula & $P 21 / c$ & $P 21 / c$ & $P-1$ \\
\hline$a(\AA)$ & $18.0244(12)$ & $13.7608(6)$ & $9.605(5)$ \\
\hline$b(\AA)$ & $8.7103(6)$ & $10.9081(5)$ & $11.502(5)$ \\
\hline$c(\AA)$ & $32.087(2)$ & $27.4964(13)$ & $14.582(5)$ \\
\hline$\alpha\left(^{\circ}\right)$ & 90 & 90 & $101.257(5)$ \\
\hline$\beta\left(^{\circ}\right)$ & $95.1860(10)$ & $99.8520(10)$ & $104.519(5)$ \\
\hline$\gamma\left({ }^{\circ}\right)$ & 90 & 90 & $105.545(5)$ \\
\hline$V\left(\AA^{3}\right)$ & $5017.0(6)$ & $4066.5(3)$ & $1441.8(11)$ \\
\hline$Z$ & 4 & 4 & 2 \\
\hline$D_{c}\left(\mathrm{~g} \mathrm{~cm}^{-3}\right)$ & 1.612 & 1.430 & 1.536 \\
\hline$\mu\left(\mathrm{mm}^{-1}\right)$ & 0.928 & 0.596 & 0.813 \\
\hline$F(000)$ & 2480 & 1792 & 684 \\
\hline Reflection collected & 35828 & 22729 & 8380 \\
\hline Unique reflections & 12534 & 7148 & 5077 \\
\hline parameters & 662 & 523 & 370 \\
\hline$R_{\text {int }}$ & 0.0440 & 0.0258 & 0.0437 \\
\hline GOF & 1.040 & 1.063 & 0.999 \\
\hline$R_{1}^{a}[I>2 \sigma(I)]$ & 0.0482 & 0.0458 & 0.0483 \\
\hline$w R_{2}^{b}$ (all data) & 0.0949 & 0.1224 & 0.0873 \\
\hline
\end{tabular}

$\mathrm{C}_{28} \mathrm{H}_{34} \mathrm{CdN}_{4} \mathrm{O}_{8}$ (667.00): C 50.37, H 5.14, N 8.40\%. Found: C 50.26, H 5.30, N 8.52\%. IR (KBr, cm $\left.{ }^{-1}\right)$ : 3440 (s), 3327 (w), 3083 (w), 2951 (w), 1688 (m), 1585 (s), 1535 (s), 1478 (m), 1391 (s), 1328 (w), 1271 (w), 1196 (w), 1127 (w), 1052 (w), 1021 (m), 864 (s), 814 (s), 783 (s), 708 (m), 619 (w), 475 (m).

\section{$2.3 X$-ray crystallography}

The single-crystal X-ray diffraction data for the title compounds were collected on a Bruker SMART APEX II with Mo $\mathrm{K} \alpha(\lambda=0.71073 \AA)$ by $\omega$ and $\theta$ scan mode at room temperature. All the structures were solved by direct methods and refined on $F^{2}$ by full-matrix least-squares methods using the SHELXS program of the SHELXTL package. ${ }^{30}$ The hydrogen atoms of the organic ligands were generated theoretically onto the specific atoms and refined isotropically with fixed thermal factors, the non-hydrogen atoms were found from the Fourier difference maps refined anisotropically. The crystallographic data and structural refinement results of compounds 1-3 are summarized in Table 1.

\section{Results and Discussion}

\subsection{Description of crystal structures of $\left[\mathrm{Cd}_{2}(\mathrm{~L})_{2}(\right.$ btec $\left.)\left(\mathrm{H}_{2} \mathrm{O}\right)_{2}\right] \cdot 3 \mathrm{H}_{2} \mathrm{O}(\mathbf{1})$}

The X-ray structural diffraction analysis indicates that compound $\mathbf{1}$ crystallizes in the monoclinic system with the $P 21 / c$ space group and shows a 3D metal-organic coordination network. The asymmetric unit of $\mathbf{1}$ consists of two crystallographically independent $\mathrm{Cd}(\mathrm{II})$ ions (Cd1, Cd2), one btec anion, two L ligands, two coordination water molecules and three lattice water molecules. As shown in Figure 1a, the Cd1 ion is seven-coordinated in a distorted pentagonal bipyramid coordination geometry, completed by four carboxyl oxygen atoms from two different btec anions [Cd1-O bond lengths: 2.324(2) $\sim 2.498(2) \AA]$, two pyridyl nitrogen atoms from two distinct L ligands [Cd1-N5 = 2.339(3), Cd1-N6 = $2.340(3) \AA]$, and one oxygen atom of a coordinated water molecule $[\mathrm{Cd} 1-\mathrm{O} 1 \mathrm{~W}=2.359(3) \AA]$. While $\mathrm{Cd} 2$ ion exhibits a typical six-coordinated distorted octahedral environment, surrounded by three carboxyl oxygen atoms from two individual btec anions $[\mathrm{Cd} 2-\mathrm{O}$ bond lengths: 2.252(2) 2.524(3) $\mathrm{A}$ ], two pyridyl nitrogen atoms $[\mathrm{Cd} 2-\mathrm{N} 1=2.301(3), \mathrm{Cd} 2-\mathrm{N} 2=2.370(3) \AA]$ from two L ligands, and one oxygen atom of the coordinated water molecule $[\mathrm{Cd} 2-\mathrm{O} 2 \mathrm{~W}=2.364(3) \AA]$, as depicted in Figure $1 \mathrm{~b}$. The bond angles around the $\mathrm{Cd}(\mathrm{II})$ ions are $82.23(10)-175.54(11)^{\circ}$ for $\mathrm{O}-\mathrm{Cd}-\mathrm{N}$, $87.45(12)-89.73(12)^{\circ}$ for $\mathrm{N}-\mathrm{Cd}-\mathrm{N}$ and $79.63(10)-$ $160.16(10)^{\circ}$ for $\mathrm{O}-\mathrm{Cd}-\mathrm{O}$, respectively.

In compound $\mathbf{1}$, the btec anions serving as the $\mu_{4}$ bridging ligands link the adjacent four $\mathrm{Cd}(\mathrm{II})$ ions to form a $2 \mathrm{D} \quad\left[\mathrm{Cd}_{2}(\mathrm{btec})\right]_{\mathrm{n}}$ polymeric layer of $\mathbf{1}$ 


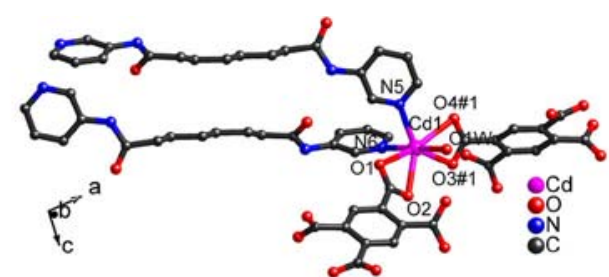

(a)

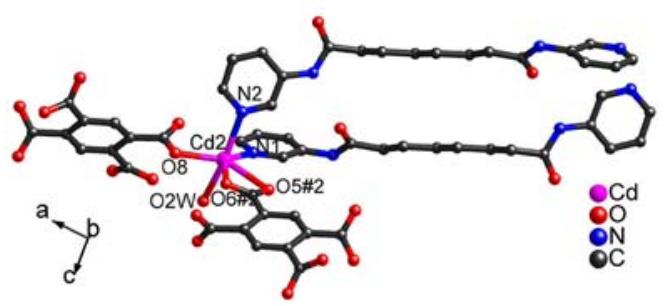

(b)

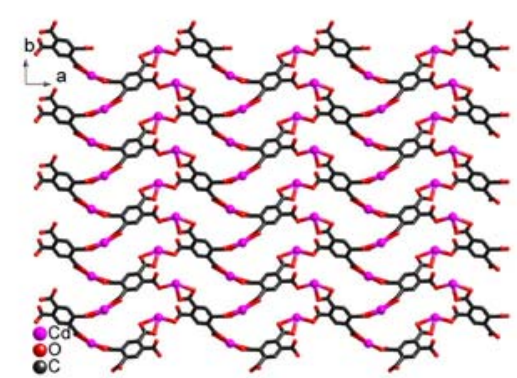

(c)

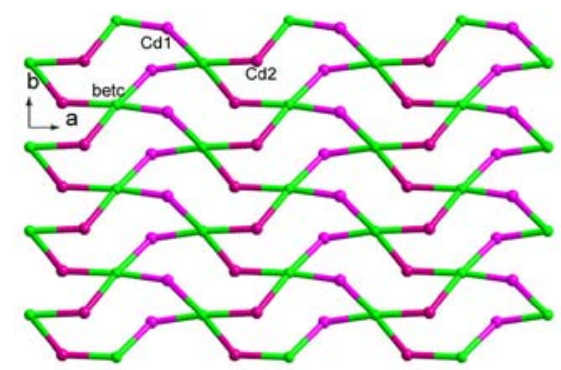

(d)

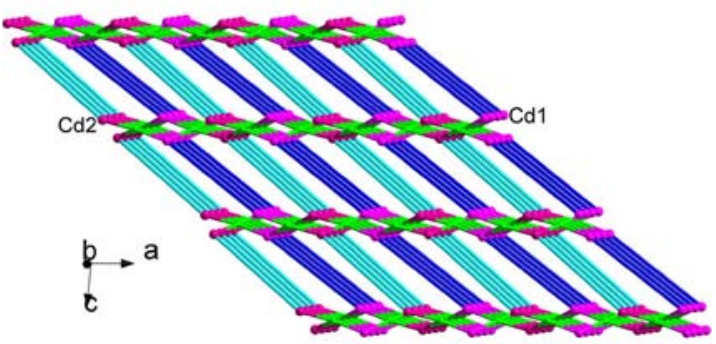

(e)

Figure 1. (a) and (b) The coordination environment of the $\mathrm{Cd}(\mathrm{II})$ ions in compound $\mathbf{1}$ (The hydrogen atoms and lattice water molecules have been omitted for clarity.); (c) The $2 \mathrm{D}\left[\mathrm{Cd}_{2}(\mathrm{btec})\right]_{\mathrm{n}}$ polymeric layer in 1; (d) Schematic of the 2D $\left[\mathrm{Cd}_{2}(\mathrm{btec})\right]_{\mathrm{n}}$ layer in 1; (e) The simplified representation of $3 \mathrm{D}\left[\mathrm{Cd}_{2}(\mathrm{~L})_{2}(\mathrm{btec})\right]_{\mathrm{n}}$ network with $\left\{6^{2} .8^{4}\right\}\left\{6^{3} .8^{3}\right\}\left\{6^{4} .8^{2}\right\}$ topology in $\mathbf{1}$.
(Figure 1c), in which the btec anion adopts a monodentate-tri(chelating) bridging coordination mode (Table 2): one carboxyl group coordinates to one $\mathrm{Cd}(\mathrm{II})$ ion with a $\mu_{1}-\eta^{1}: \eta^{0}$ mode, and other three coordinate, respectively, with three $\operatorname{Cd}(\mathrm{II})$ ions with a $\mu_{1}-\eta^{1}: \eta^{1}$ mode. Furthermore, the adjacent 2D layers are connected by the L ligands to form a 3D framework of $\mathbf{1}$, as shown in Figure 1d (and Figure S1a, Supporting Information). Interestingly, the $\mu_{2}$-bridging $\mathrm{L}$ ligands exhibit two kinds of conformations ( $\mathrm{L}^{\mathrm{a}}$ and $\mathrm{L}^{\mathrm{b}}$ ), which bridge two $\mathrm{Cd}(\mathrm{II})$ ions from the adjacent $2 \mathrm{D}$ layers to build two different $\left\{\mathrm{Cd}_{2}(\mathrm{~L})_{2}\right\}$ dinuclear loops (Figure $\mathrm{S} 1 \mathrm{~b}$ and $1 \mathrm{c}$ ). $\mathrm{L}^{\mathrm{a}}$ links two $\mathrm{Cd} 1$ ions with the non-bonding $\mathrm{Cd} 1 \cdots \mathrm{Cd} 1$ distance of $19.544 \AA$, and the dihedral angle between its two pyridyl rings is $80.822^{\circ}$. While $\mathrm{L}^{\mathrm{b}}$ connects two $\mathrm{Cd} 2$ ions with the non-bonding $\mathrm{Cd} 2 \cdots \mathrm{Cd} 2$ distance of $19.455 \AA$, and the dihedral angle between its two pyridyl rings is $71.794^{\circ}$ (Table 2 ).

A better insight into the framework of $\mathbf{1}$ can be achieved by the procedure of reducing multidimensional structures to simple nodes and connection networks known as the topological approach. Both $\mathrm{Cd} 1$ and $\mathrm{Cd} 2$ ions are surrounded by four organic ligands (two $\mathrm{L}$ and two btec) and can simply be regarded as 4-connected nodes. Each btec is linked to four Cd(II) ions, therefore, defined as a 4-connected node. The ligand L ligating with two $\mathrm{Cd}(\mathrm{II})$ ions only serves as a linear linker. The topological structure of $\mathbf{1}$ can be considered to be a trinodal $(4,4,4)$-connected network, its Schläfli symbol is $\left\{6^{2} .8^{4}\right\}\left\{6^{3} .8^{3}\right\}\left\{6^{4} .8^{2}\right\}$, as shown in Figure 1e.

\subsection{Description of crystal structures of $[C d(H L)(b t b)](2)$}

Compound 2 was prepared by the similar procedure used for compound 1, except that $\mathrm{H}_{3}$ btb was used instead of $\mathrm{H}_{4}$ btec. It crystallizes in monoclinic crystal system with $P 21 / c$ space group. Single crystal X-ray diffraction analysis reveals that the asymmetric unit of $\mathbf{2}$ consists of one $\mathrm{Cd}$ (II) ion, one btb anion and one protonated HL ligand. Each $\mathrm{Cd}(\mathrm{II})$ ion is six-coordinated and displays a distorted octahedral geometry supplied by five carboxyl oxygen atoms from three different btb anions [Cd1-O bond distances: 2.172(3) 2.646(3) $\mathrm{A}$ ] and one pyridyl nitrogen atom from a ligand $\mathrm{L}[\mathrm{Cd} 1-$ $\mathrm{N} 1=2.285(3) \AA]$ (Figure 2a). In 2, each btb anion adopts a monodentate-bi(chelating) coordination mode coordinated to three $\mathrm{Cd}(\mathrm{II})$ ions as a $\mu_{3}$-bridging ligand (Table 2), its one carboxyl group coordinates to one $\mathrm{Cd}(\mathrm{II})$ ion with a $\mu_{1}-\eta^{1}: \eta^{0}$ mode, and other two carboxyl groups respectively coordinate with two $\mathrm{Cd}(\mathrm{II})$ ions with a $\mu_{1}-\eta^{1}: \eta^{1}$ mode. The $\mathrm{Cd}(\mathrm{II})$ ions are connected by btb anions to give a $3 \mathrm{D}[\mathrm{Cd}(\mathrm{btb})]_{\mathrm{n}}^{\mathrm{n}-}$ polymeric 
Table 2. Coordination modes of Cd(II) ions, three polycarboxylates (btec, btb, pda) and the flexible bis(pyridyl)-bis(amide) ligands (L) in compounds $\mathbf{1}-\mathbf{3}$.

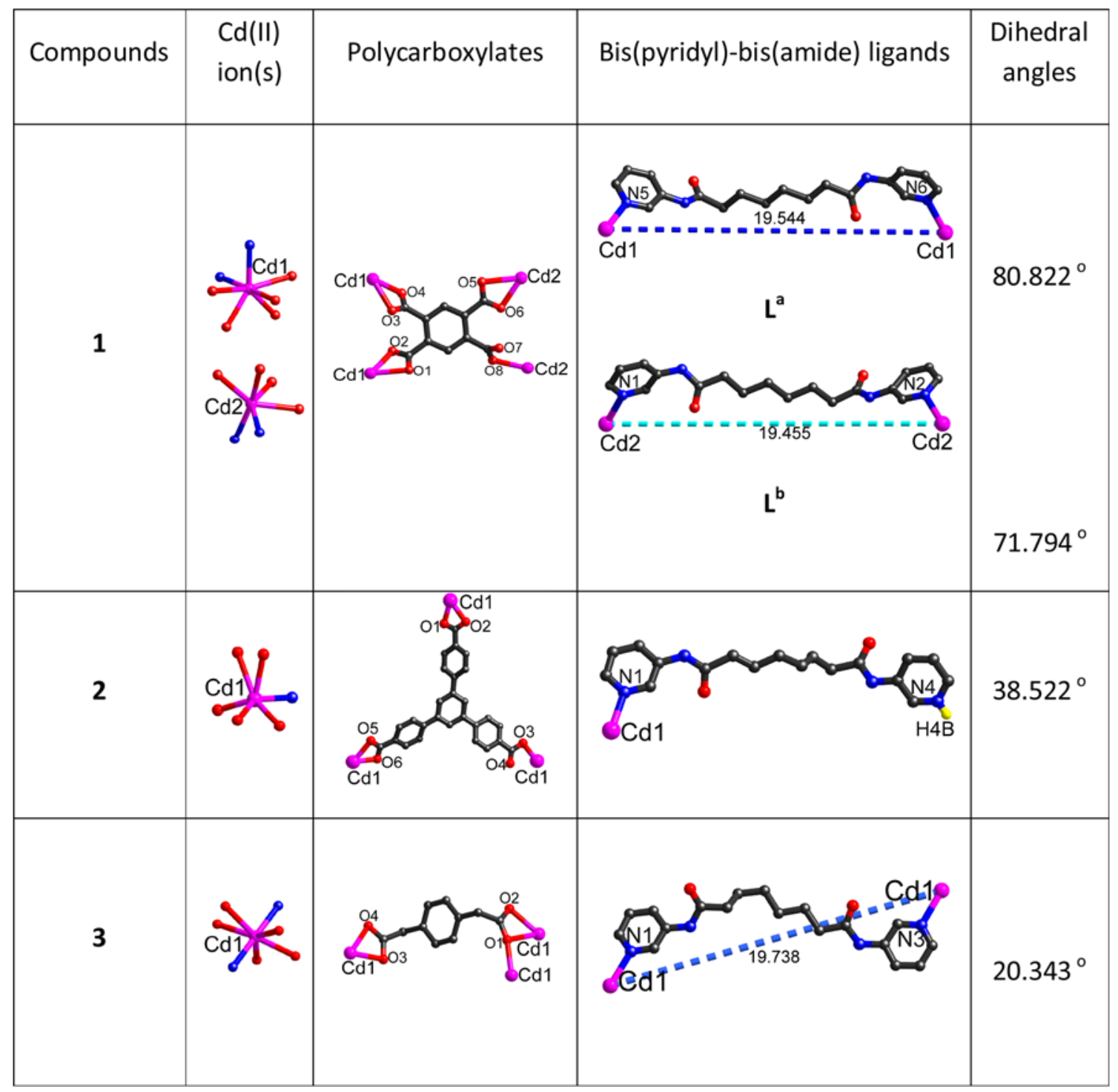

framework (Figure 2b and Figure S2 in SI). If Cd(II) ion and the btb can be respectively considered as the three-connected nodes, the $3 \mathrm{D}[\mathrm{Cd}(\mathrm{btb})]_{\mathrm{n}}^{\mathrm{n}-}$ structure of 2 is a binodal 3,3-connected network with the point symbol of $\left\{10^{3}\right\}$ (Figure 2c). In the 3D $[\mathrm{Cd}(\mathrm{btb})]_{\mathrm{n}}^{\mathrm{n}-}$ framework, the big cavities with the dimensional size of $21.817 \AA \times 25.557 \AA$ can be seen (Figure S2 in SI). In addition, the $\mathrm{L}$ ligand is protonated and displays a monodentate coordination mode in $\mathbf{2}$, which coordinates to one $\mathrm{Cd}(\mathrm{II})$ ion by its a pyridyl nitrogen atom (Table 2). The dihedral angle between two pyridyl rings of L ligand is $38.522^{\circ}$ (Table 2). The L ligands are hinged at the $3 \mathrm{D}$ $[\mathrm{Cd}(\mathrm{btb})]_{\mathrm{n}}^{\mathrm{n}-}$ framework and occupied in the voids of the 3D framework (Figure 2d), which leads to only ca. $6.6 \%$ voids for 2 . To the best of our knowledge, the compound 2 represents the first example of coordination polymer constructed from the bis(pyridyl)-bis(amide) and $\mathrm{H}_{3}$ btb ligands.

\subsection{Description of crystal structures of \\ $[\mathrm{Cd}(\mathrm{L})(\mathrm{pda})] \cdot 2 \mathrm{H}_{2} \mathrm{O}(\mathbf{3})$}

Different from $\mathrm{H}_{4}$ btec in $\mathbf{1}$ and $\mathrm{H}_{3}$ btb in 2, the selection of $\mathrm{H}_{2}$ pda results in constructing a $2 \mathrm{D}$ polymeric layer of compound 3. Single crystal X-ray diffraction study reveals that compound $\mathbf{3}$ crystallizes in the triclinic system with $P-1$ space group and its asymmetric unit consists of one crystallographical independent $\mathrm{Cd}$ (II) ion, one pda anion, one L ligand and two lattice water molecules. As depicted in Figure $3 \mathrm{a}$, the $\mathrm{Cd}(\mathrm{II})$ ion is seven-coordinated $\left\{\mathrm{CdO}_{5} \mathrm{~N}_{2}\right\}$ fashion by five carboxyl oxygen atoms belonging to three individual pda 


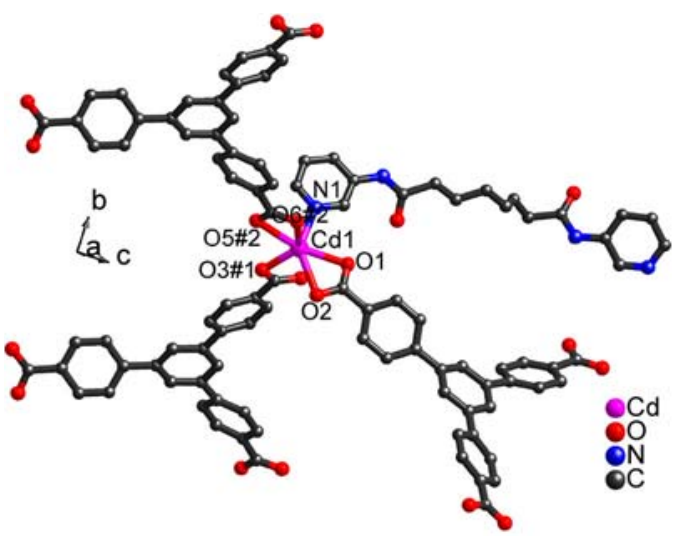

(a)

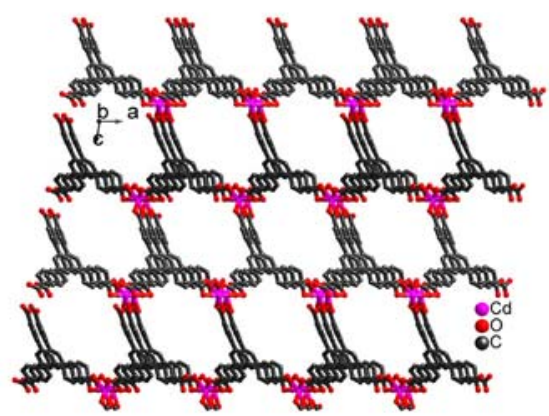

(b)

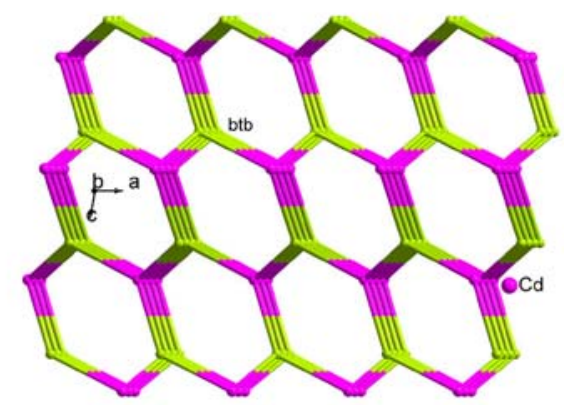

(c)

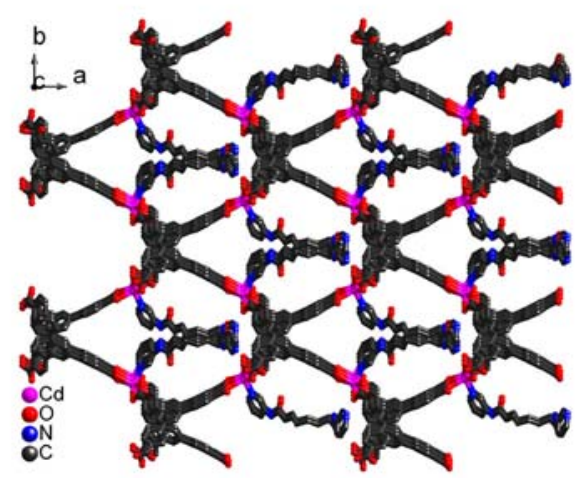

(d)

Figure 2. (a) The coordination environment of the $\mathrm{Cd}(\mathrm{II})$ ion in compound 2 (the $\mathrm{H}$ atoms have been omitted for clarity.); (b) View of the 3D $[\mathrm{Cd}(\mathrm{btb})]_{\mathrm{n}}{ }^{\mathrm{n}-}$ framework in 2; (c) The simplified representation of the $3 \mathrm{D}[\mathrm{Cd}(\mathrm{btb})]_{\mathrm{n}}{ }^{\mathrm{n}-}$ framework with $\left\{10^{3}\right\}$ topology in 2 ; (d) The 3D $[\mathrm{Cd}(\mathrm{btb})(\mathrm{HL})]$ network of 2 . anions [the $\mathrm{Cd}-\mathrm{O}$ distances: $\mathrm{Cd} 1-\mathrm{O} 1=2.353(4) \AA$, $\mathrm{Cd} 1-\mathrm{O} 1 \# 2=2.470(4) \AA, \mathrm{Cd} 1-\mathrm{O} 2 \# 2=2.352(3) \AA$, $\mathrm{Cd} 1-\mathrm{O} 3 \# 3=2.413(3), \mathrm{Cd} 1-\mathrm{O} 4 \# 3=2.455(4)]$ and two pyridyl nitrogen atoms (N1 and N3\#1) of two separated L ligands [Cd1-N1 = 2.358(4) $\AA, \mathrm{Cd} 1-\mathrm{N} 3 \# 1=$ 2.342(4) $\AA$ ] , completing a distorted pentagonal bipyramid geometry. In 3 , each pda anion bridges three $\mathrm{Cd}(\mathrm{II})$ ions by its two carboxyl groups with a bi(chelating)monodentate coordination mode (Table 2), its one carboxyl group coordinates to one $\mathrm{Cd}(\mathrm{II})$ ion with a $\mu_{1}-\eta^{1}: \eta^{1}$ mode, and the other coordinates to two $\mathrm{Cd}(\mathrm{II})$ ion with a $\mu_{2}-\eta^{1}: \eta^{2}$ mode. The $\mathrm{Cd}(\mathrm{II})$ ions are linked by pda anions with the $\mu_{3}$-bridging mode to build a $1 \mathrm{D}[\mathrm{Cd}(\mathrm{pda})]_{\mathrm{n}}$ ribbon chain (Figure $3 \mathrm{~b}$ ). In addition, the L ligands with a bidentate coordination mode connect two $\mathrm{Cd}(\mathrm{II})$ ions to form a $1 \mathrm{D}[\mathrm{Cd}(\mathrm{L})]_{\mathrm{n}}$ wave-like chain (Figure S3a in SI), in which the $\mathrm{Cd} 1 \cdots \mathrm{Cd} 1$ distance is $19.738 \AA$ and the dihedral angle between the two pyridine rings is $20.343^{\circ}$. The combination of two kinds of 1D chains results in the formation of an interesting 2D double-layer structure (Figure 3c). Topologically, if $\mathrm{Cd}$ (II) ion is considered as a 5-connected node, the bridging ligand pda is considered as a 3connected node and the L ligand is serving as the linker, the 2D double layer of compound 3 represents a 3,5connected framework with $\left(4^{2} \cdot 6^{7} \cdot 8\right)\left(4^{2} \cdot 6\right)$ topology (Figure 3d). Furthermore, the adjacent 2D double layers of $\mathbf{3}$ are connected by the hydrogen bonding interactions to produce a 3D supramolecular network (Figure $\mathrm{S} 3 \mathrm{~b}$ ). Three types of hydrogen-bonding interactions are observed: one is between the nitrogen atom (N2) from the amide group of $\mathrm{L}$ ligand and the carboxyl oxygen atom $(\mathrm{O} 4)$ of pda anion $[\mathrm{N} 2-\mathrm{H} 2 \cdots \mathrm{O} 4=2.949(6) \AA]$, the second is between the oxygen atom $(\mathrm{O} 2 \mathrm{~W})$ from the lattice water and the carboxyl oxygen atoms (O3) of pda anion $[\mathrm{O} 2 \mathrm{~W}-\mathrm{H} 2 \mathrm{WA} \cdots \mathrm{O} 3=2.838(6) \AA]$, another is between the oxygen atom $(\mathrm{O} 2 \mathrm{~W})$ from the lattice water and the carbonyl oxygen atoms $(\mathrm{O} 6)$ of L ligand [O2W$\mathrm{H} 2 \mathrm{WB} \cdots \mathrm{O} 6=2.816(6) \AA ̊ ․$

\subsection{Effect of aromatic polycarboxylates and the coordiantion modes of the flexible bis(pyridyl)-bis(amide) ligand on the structural diversities of three $C d(I I)$ compounds}

As known, the bridging organic ligands play the crucial role in constructing the coordination frameworks of the metal-organic compounds. In this work, when three kinds of aromatic polycarboxylates $\mathrm{H}_{4}$ btec, $\mathrm{H}_{3}$ btb and $\mathrm{H}_{2}$ pda were selected as bridging ligands to be introduced into the Cd-L systems, three new Cd(II) compounds showing diverse structures were prepared, which 


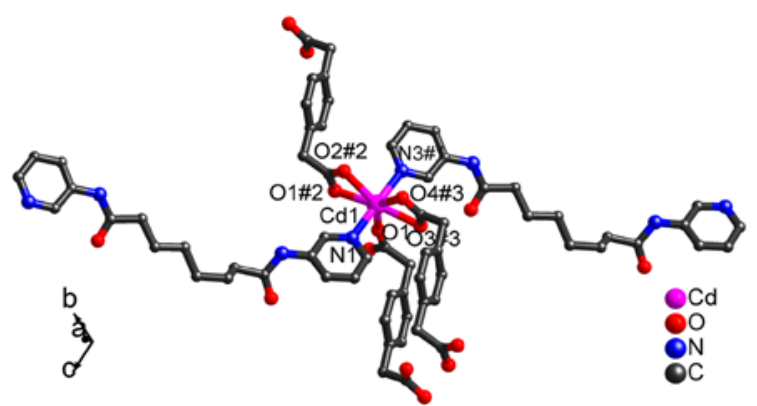

(a)

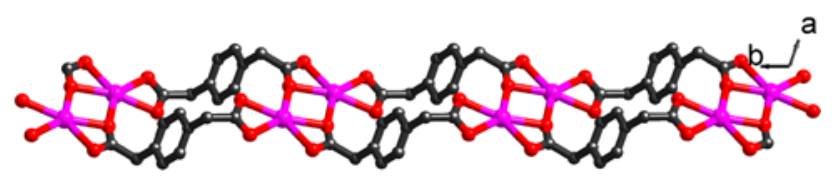

(b)

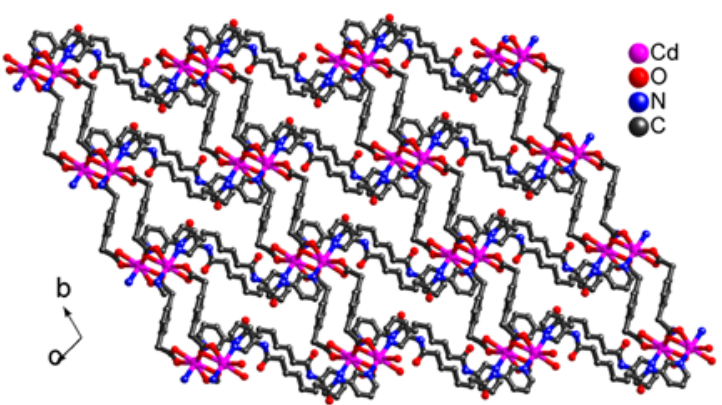

(c)

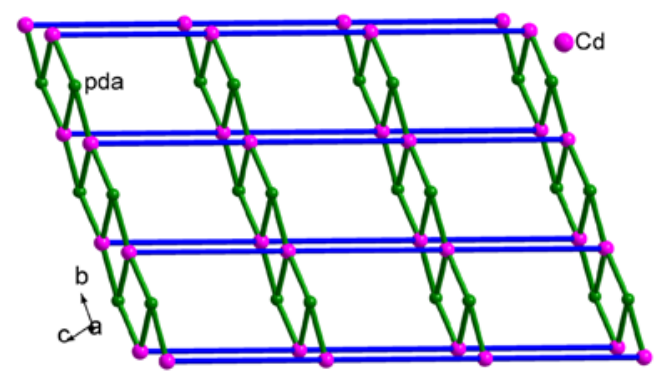

(d)

Figure 3. (a) The coordination environment of the Cd(II) ion in compound $\mathbf{3}$ (The hydrogen atoms and lattice water molecules have been omitted for clarity.); (b) View of the 1D $[\mathrm{Cd}(\mathrm{pda})]_{\mathrm{n}}$ ribbon-like chain in 3; (c) View of the 2D $[\mathrm{Cd}(\mathrm{L})(\mathrm{pda})]_{n}$ layer along $a$-axis in 3; (d) Schematic of the 2D layer of 3 .

revealed the effect of intrinsic structures for these polycarboxylates with different carboxyl numbers and sizes. In the three polycarboxylates, $\mathrm{H}_{4}$ btec has four carboxyl groups, but its size is the relatively small; $\mathrm{H}_{3}$ btb has three carboxyl groups, while its size is the largest; although $\mathrm{H}_{2}$ pda has two carboxyl groups, its acetic group is the most flexible. For three Cd(II) compounds, all of the carboxyl oxygen atoms from polycarboxylates are coordinated with $\mathrm{Cd}(\mathrm{II})$ ions (Table 2 ). In $\mathbf{1}$, tetracarboxylates btec $^{4-}$ anions as the $\mu_{4}$-bridging ligands linked the adjacent $\mathrm{Cd}(\mathrm{II})$ ions to form a $2 \mathrm{D}\left[\mathrm{Cd}_{2}(\mathrm{btec})\right]_{\mathrm{n}}$ polymeric layer. In $\mathbf{2}$, tricarboxylates $\mathrm{btb}^{3-}$ anions with the $\mu_{3}$-bridging mode connected $\mathrm{Cd}$ (II) ions to generate a $3 \mathrm{D}[\mathrm{Cd}(\mathrm{btb})]_{\mathrm{n}}^{\mathrm{n}-}$ coordination network. In 3, dicarboxylates $\mathrm{pda}^{2-}$ anions serving as the $\mu_{3}$-bridging ligands to build a $1 \mathrm{D}[\mathrm{Cd}(\mathrm{pda})]_{\mathrm{n}}$ ribbon chain. Obviously, three polycarboxylates play the key role in bridging $\mathrm{Cd}(\mathrm{II})$ ions to construct diverse coordination frameworks.

Although, the same flexible bis(pyridyl)-bis(amide) ligand L was used in the three $\mathrm{Cd}(\mathrm{II})$ compounds, its coordiantion modes or coordination conformations were different in these compounds (Table 2), which lead to bridge the adjacent $\mathrm{Cd}(\mathrm{II})$ ions to produce different structure units. In $\mathbf{1}$ and $\mathbf{3}$, L ligands adopt the bidentate bridging coordination modes, but they demonstrate two kinds of coordination configurations: cis-configuration in $\mathbf{1}$ and trans-configuration in $\mathbf{3}$. Ligand $\mathrm{L}$ link two $\mathrm{Cd}$ (II) ions into two different $\left\{\mathrm{Cd}_{2}(\mathrm{~L})_{2}\right\}$ dinuclear loops with $\mathrm{Cd} \cdots \mathrm{Cd}$ distances of $19.544 \AA$ and $19.455 \AA$ (the dihedral angle of its two pyridyl rings: $80.822^{\circ}$ and $71.794^{\circ}$ ) in $\mathbf{1}$, while in $\mathbf{3}$ ligands L bridge the adjacent $\mathrm{Cd}(\mathrm{II})$ ions to give a $1 \mathrm{D}$ zigzag chain $(\mathrm{Cd} \cdots \mathrm{Cd}$ distance: $19.738 \AA$ A, dihedral angles: $20.343^{\circ}$ ). Different from compounds $\mathbf{1}$ and $\mathbf{3}$, the ligands $\mathrm{L}$ are protonated and display the monodentate coordination mode in $\mathbf{2}$, in which the dihedral angle of its two pyridyl rings is $38.522^{\circ}$.

For these polycarboxylates and the bis(pyridyl)bis(amide) ligands, their coordination modes, the flexibilities and sizes are different, which lead to the diverse coordination numbers and modes of the $\mathrm{Cd}(\mathrm{II})$ ions in three title compounds (Table 2). In 1, there are two crystallographically independent $\mathrm{Cd}(\mathrm{II})$ ions: a six-coordinated $\left\{\mathrm{CdN}_{2} \mathrm{O}_{4}\right\}$ distorted octahedral geometry and a seven-coordinated $\left\{\mathrm{CdN}_{2} \mathrm{O}_{5}\right\}$ distorted pentagonal bipyramid geometry. For 2, Cd(II) ions are six-coordinated by one pyridyl nitrogen atom of L ligands and five oxygen atoms in $\left\{\mathrm{CdNO}_{5}\right\}$ styles. In 3, the $\mathrm{Cd}(\mathrm{II})$ ions adopt the seven-coordinated $\left\{\mathrm{CdN}_{2} \mathrm{O}_{5}\right\}$ modes.

Finally, $\mathbf{1}$ is a 3D metal-organic coordination network based on the $2 \mathrm{D}\left[\mathrm{Cd}_{2}(\mathrm{btec})\right]_{\mathrm{n}}$ layers and the bidentate bis(pyridyl)-bis(amide) ligands $\mathrm{L}$, which represents a $(4,4,4)$-connected $\left\{6^{2} .8^{4}\right\}\left\{6^{3} .8^{3}\right\}\left\{6^{4} .8^{2}\right\}$ topology. While 2 is a $3 \mathrm{D}$ polymeric framework with $(3,3)$-connected $\left\{10^{3}\right\}$ topology containing the $3 \mathrm{D}[\mathrm{Cd}(\mathrm{btb})]_{\mathrm{n}}^{\mathrm{n}-}$ network and the monodentate HL ligand, its topological structure is different from $\mathbf{1}$. Compound 3 represents a 2D double layer with 3,5 -connected $\left(4^{2} \cdot 6^{7} \cdot 8\right)\left(4^{2} \cdot 6\right)$ 
topology. Although many factors are involved, the different polycarboxylates with the various structures, sizes and flexibilities as well as the flexible bis(pyridyl)bis(amide) ligands with the different conformations or coordination modes play the important role in determining the final coordination structures. The research results show that the appropriate combination of different polycarboxylates and the flexible bis(pyridyl)-bis(amide) ligands may result in constructing new coordination compounds with diverse structures.

\subsection{Powder X-ray diffraction of compounds 1-3}

The crystal phase purities of the title compounds were evidenced by similarity of the simulated and experimental powder X-ray diffraction (PXRD) patterns, as shown in Figures S7-S9 in Supporting Information. For compounds 1-3, their diffraction peaks of the simulated and experimental patterns match well in key positions, indicating the phase purities.

\subsection{Thermal stability analyses of compounds 1-3}

The thermal stabilities of the title compounds were studied and their thermogravimetric (TG) analyses were performed in the temperature range of $25-950{ }^{\circ} \mathrm{C}$ (Figure $\mathrm{S} 10$ in SI). For compounds $\mathbf{1}$ and $\mathbf{3}$, their TG curves are obvious two-step weight loss processes, while the TG curve for compound $\mathbf{2}$ is a one-step weight loss process. The first step with weight loss $8.01 \%$ for $\mathbf{1}$ and $5.71 \%$ for 3 occurs in the range of $150-350{ }^{\circ} \mathrm{C}$ for 1 and $160-260{ }^{\circ} \mathrm{C}$ for 3 , which can be attributed to the loss of the coordinated water molecules and lattice water molecules (calcd.: $7.39 \%$ for $\mathbf{1}, 5.40 \%$ for 3 ). The second step may be ascribed to the weight loss of ligands $\mathrm{L}$ and btec/pda. The remaining weight of the final residue ( $21.50 \%$ for $\mathbf{1}, 20.06 \%$ for 3 ) corresponds to the percentage $(21.09 \%$ for $\mathbf{1}, 19.25 \%$ for $\mathbf{3})$ of $\mathrm{Cd}$ and $\mathrm{O}$ components, suggesting that $\mathrm{CdO}$ should be the residual product. In the TG curve of $\mathbf{2}$, only one weight loss step could be seen between $400{ }^{\circ} \mathrm{C}$ and $550{ }^{\circ} \mathrm{C}$, corresponding to the decomposition of bridging ligands $\mathrm{L}$ and $\mathrm{btb}$. The final residue of $\mathbf{2}$ with weight $14.90 \%$ is presumed to be $\mathrm{CdO}$ (calcd. 14.67\%).

\subsection{Fluorescent properties of compounds 1-3}

The fluorescent properties of three Cd(II) compounds and the free flexible bis(pyridyl)-bis(amide) ligand $\mathrm{L}$ were studied in the solid state at room temperature (Figure 4). The fluorescent emission band of the ligand $\mathrm{L}$ can be observed at $409 \mathrm{~nm}\left(\lambda_{\mathrm{ex}}=320 \mathrm{~nm}\right)$, which may be attributed to the intraligand $\pi \rightarrow \pi^{*}$

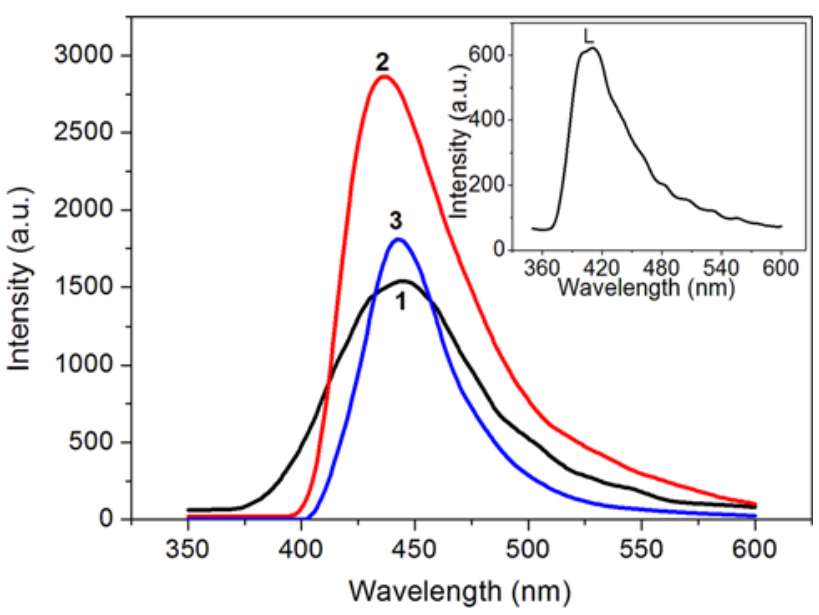

Figure 4. The emission spectra of compounds 1-3 in solid state at room temperature $\left(\lambda_{e x}=320 \mathrm{~nm}\right)$. (The insert is the emission spectrum of the free ligand $\mathrm{L}, \lambda_{\mathrm{ex}}=320 \mathrm{~nm}$ ).

or $\mathrm{n} \rightarrow \pi^{*}$ transitions. ${ }^{31,32}$ The emission bands for the three $\mathrm{Cd}(\mathrm{II})$ compounds were observed at $443 \mathrm{~nm}, 435$ $\mathrm{nm}$ and $442 \mathrm{~nm}\left(\lambda_{\mathrm{ex}}=320 \mathrm{~nm}\right)$, respectively. Comparing with the emission peaks of free ligand $\mathrm{L}$, the red shift of ca. $34 \mathrm{~nm}, 26 \mathrm{~nm}$ and $33 \mathrm{~nm}$ for compounds $\mathbf{1}-\mathbf{3}$ may be assigned to the ligand-to-metal charge-transfer (LMCT). ${ }^{27,32}$

Additionally, the influences of organic solvent molecules on the fluorescent intensities of three $\mathrm{Cd}(\mathrm{II})$ compounds have also been studied at room temperature, the fluorescent behaviors of 1-3 containing various solvent molecules (designated as 1-solvent, 2solvent and 3-solvent, respectively) were recorded as shown in Figure 5. Compounds $\mathbf{1}-\mathbf{3}$-solvent were prepared by introducing $\mathbf{1}-\mathbf{3}(8.0 \mathrm{mg})$ as a fine powder into Dimethylformamide (DMF), Benzene, Acetone, Tetrahydrofuran (THF), $\mathrm{CH}_{3} \mathrm{OH}(\mathrm{MeOH}), \mathrm{CH}_{3} \mathrm{CH}_{2} \mathrm{OH}$ (EtOH), $\mathrm{CH}_{3} \mathrm{CN}, \mathrm{CH}_{2} \mathrm{Cl}_{2}$, Cyclohexane, Methylbenzene, Formaldehyde, Dimethylsulfoxide (DMSO), $\mathrm{CCl}_{4}$ or Ethanediol $(5.0 \mathrm{~mL}$ in each case) for $72 \mathrm{~h}$. Then ultrasonic processing, filtering and drying in air, the fluorescent samples of 1-3-solvent were obtained, their fluorescent spectra were measured at room temperature (Figure 5). When compared to the three $\mathrm{Cd}(\mathrm{II})$ compounds, for $\mathbf{1}$, all of the fluorescent intensities of 1-solvent were obviously decreased; for $\mathbf{2}$, only the fluorescence intensity of $\mathbf{2}-\mathrm{MeOH}$ was enhanced, and other solvent molecules resulted in the decrease of fluorescent intensity with different degrees; for $\mathbf{3}$, the fluorescence intensities of 3-DMF, 3-Acetone, 3-EtOH, 3-MeOH, 3-DMSO were enhanced, while the decrease of fluorescent intensity with different degrees was observed for other 3-solvent structures. The most significant fluorescence quenching was found in 1-THF,2-Cyclohexane and 3-Formaldehyde, respectively (Figure S11 in SI). 


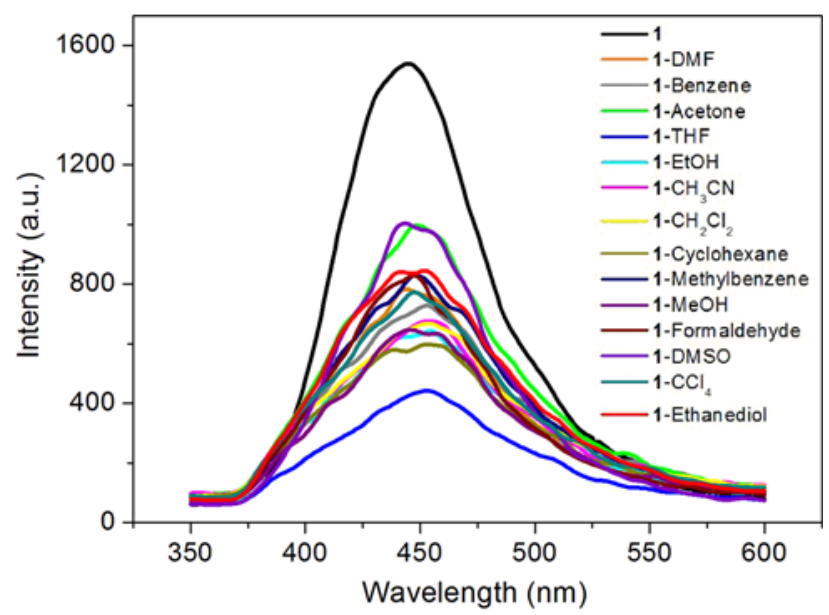

(a)

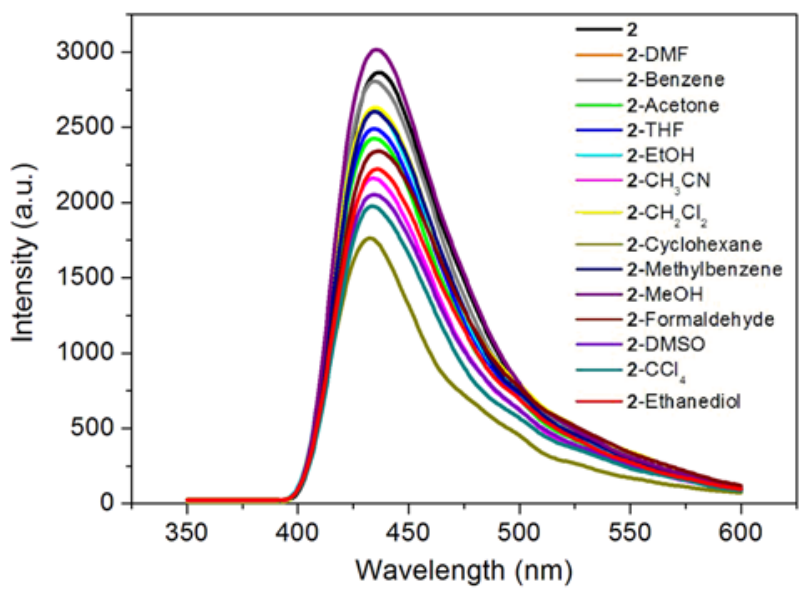

(b)

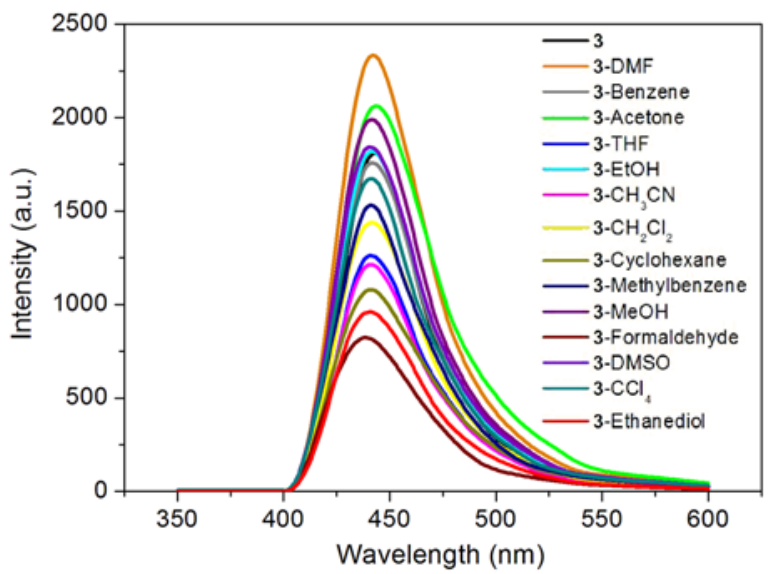

(c)

Figure 5. (a) The fluorescent spectra of 1-solvents in various solvents $\left(\lambda_{\mathrm{ex}}=320 \mathrm{~nm}\right)$; (b) The fluorescent spectra of 2 -solvent in various solvents $\left(\lambda_{\mathrm{ex}}=320 \mathrm{~nm}\right)$; (c) The fluorescent spectra of 3 -solvent in various solvents $\left(\lambda_{\mathrm{ex}}=320 \mathrm{~nm}\right)$.

The experimental results reveal that the various solvent molecules in the voids of networks of 1-3 display significant influences on their fluorescent intensities. The title $\mathrm{Cd}(\mathrm{II})$ compounds may be the potential candidates

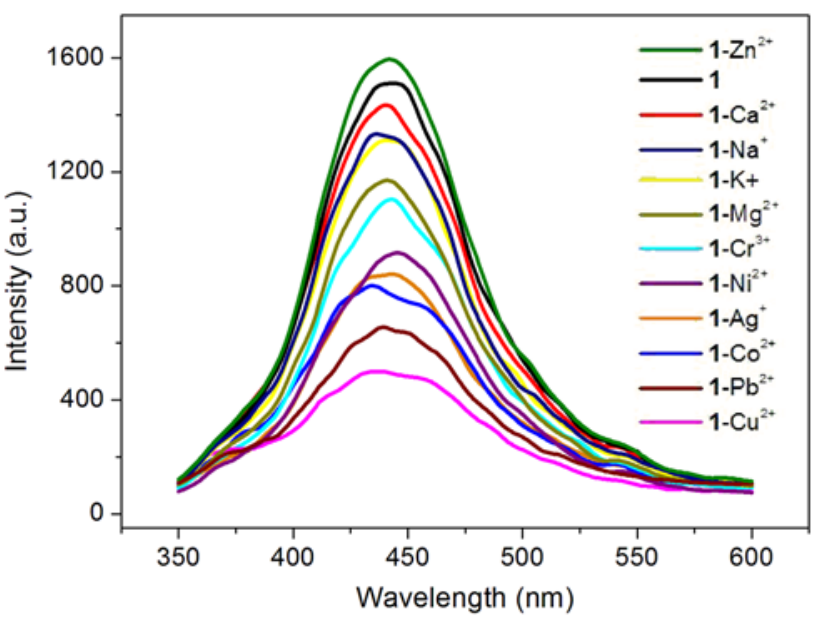

(a)

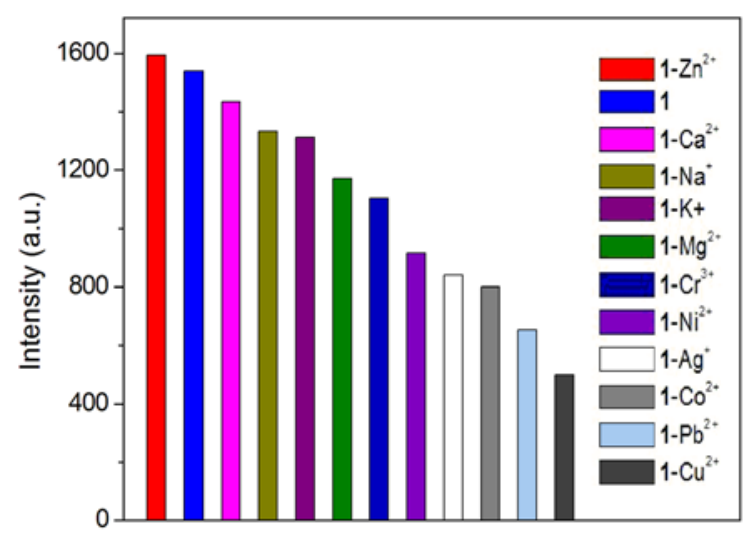

(b)

Figure 6. (a) The fluorescent spectra of $1-\mathrm{M}^{\mathrm{n}+}$ for various metal ions in aqueous solutions; (b) The fluorescence intensity histogram of $1-\mathrm{M}^{\mathrm{n}+}$.

for fluorescent sensing to detect various organic solvent molecules.

In order to investigate the effect of diverse metal ions on the fluorescent properties, the sensing behavior of $\mathbf{1}$ has been tested to probe the metal ions in aqueous solution. The as-synthesized compound $\mathbf{1}$ was grinded and dispersed in distilled water with $0.01 \mathrm{~mol} \mathrm{~L}^{-1} \mathrm{M}\left(\mathrm{NO}_{3}\right)_{\mathrm{n}}$ $\left(\mathrm{M}=\mathrm{Zn}^{2+}, \mathrm{Ca}^{2+}, \mathrm{Na}^{+}, \mathrm{K}^{+}, \mathrm{Mg}^{2+}, \mathrm{Cr}^{3+}, \mathrm{Ni}^{2+}, \mathrm{Ag}^{+}\right.$, $\mathrm{Co}^{2+}, \mathrm{Pb}^{2+}$ and $\mathrm{Cu}^{2+}$ for $24 \mathrm{~h}$ to form the $1-\mathrm{M}^{\mathrm{n}+}$ for sensing experiments. When compared to compound $\mathbf{1}$, there exists a slight fluorescence enhancement only for $1-\mathrm{Zn}^{2+}$ (Figure 6a). In contrast, other metal ions show the different quenching effect depending on the nature of metal ions, especially for $\mathrm{Cu}^{2+}$ ion for which significant quenching was observed, as shown in Figure $6 \mathrm{~b}$. The preliminary experimental result implies that compound 1 could be a potential fluorescent sensing material for detecting various metal ions. 


\section{Conclusions}

Three new $\mathrm{Cd}(\mathrm{II})$ coordination compounds have been successfully obtained under hydrothermal conditions by using flexible mixed-ligands bis(pyridyl)-bis(amide) and three different aromatic polycarboxylates $\left(\mathrm{H}_{4} \mathrm{btec}\right.$, $\mathrm{H}_{3}$ btb, $\mathrm{H}_{2}$ pda), 1-3. The three $\mathrm{Cd}(\mathrm{II})$ compounds exhibit different coordination structures with 3D networks for 1-2 and a 2D framework for 3. Three polycarboxylates with different carboxyl numbers and structures have great influence on the structures of the three Cd(II) compounds. The fluorescent properties and the fluorescent sensing behavior towards organic solvents or metal ions imply that the title $\mathrm{Cd}$ (II) compounds may be potential candidates for fluorescent and fluorescent sensing materials.

\section{Supplementary Information (SI)}

Crystallographic data for the structures reported in the paper have been deposited in the Cambridge Crystallographic Data Center with CCDC reference numbers 1544804 for $\mathbf{1}$, 1544807 for $\mathbf{2}$ and 1544805 for $\mathbf{3}$. These data can be obtained free of charge from The Cambridge Crystallographic Data Centre via http://www.ccdc.cam.ac.uk/conts/retrieving.html, or from the Cambridge Crystallographic Data Centre, 12 Union Road, Cambridge CB2 1EZ, UK; fax: (+44) 1223336-033; or e-mail: deposit@ccdc.cam.ac.uk. The tables of selected bond lengths and angles, related hydrogen bonding geometries, as well as additional figures, IR spectra, PXRD and TG curves for compounds $\mathbf{1 - 3}$ are available at www.ias. ac.in/chemsci.

\section{Acknowledgements}

The support of the National Natural Science Foundation of China (No. 21501013, 21401010 and 21671025) and Program for Distinguished Professor of Liaoning Province (No. 2015399) are gratefully acknowledged.

\section{References}

1. Suh M P, Park H J, Prasad T K and Lim D W 2012 Hydrogen Storage in Metal-Organic Frameworks Chem. Rev. 112782

2. Yoon M, Srirambalaji R and Kim K 2012 Homochiral Metal-Organic Frameworks for Asymmetric Heterogeneous Catalysis Chem. Rev. 1121196

3. Lee C H, Wu J Y, Lee G H, Peng S M, Jiang J C and Lu K L 2014 Correlation of Mesh Size of Metal-Carboxylate Layer with Degree of Interpenetration in Pillared-Layer Frameworks Cryst. Growth Des. 145608

4. Lee $\mathrm{C} \mathrm{H}$, Wu J Y, Lee G H, Peng S M, Jiang J C and Lu K L 2015 Amide-containing zinc(II) metal-organic layered networks: a structure- $-\mathrm{CO}_{2}$ capture relationship Inorg. Chem. Front. 2477
5. Huang Y J, Pan Y R, Du G and Cao Y X 2016 Extended structures of two coordination polymers based on 1,10-phenanthroline derivatives: Preparation, structural characterization and properties J. Chem. Sci. 128 459

6. Sutradhar D, Chowdhury H, Koner S, Roy S and Ghosh B K 2016 Two new hexacoordinated coordination polymers of cadmium(II) containing bridging units only: Syntheses, structures and molecular properties J. Chem. Sci. 1281377

7. Rajput L, Kim D and Lah M S 2013 Conformational control of ligands to create a finite metal-organic cluster and an extended metal-organic framework CrystEngComm 15259

8. Huang S Y, Li J Q, Liu S J, Ning Y, Meng L N, Li J Y, Luo M B and Luo F 2014 Construction and modulation of structural diversity in acylamide-MOFs CrystEngComm 165608

9. Chen M M, Li H X and Lang J P 2016 Two Coordination Polymers and Their Silver(I)-Doped Species: Synthesis, Characterization, and High Catalytic Activity for the Photodegradation of Various Organic Pollutants in Water Eur. J. Inorg. Chem. 20162508

10. Zhang X, Wang Z J, Chen S G, Shi Z Z, Chen J X and Zheng H G 2017 Cd-Based metal-organic frameworks from solvothermal reactions involving in situ aldimine condensation and the highly sensitive detection of $\mathrm{Fe}^{3+}$ ions Dalton Trans. 462332

11. Ge F Y, Ma X, Guo D D, Zhu L N, Deng Z P, Huo L $\mathrm{H}$ and Gao S 2017 Syntheses, Structural Evolutions, and Properties of Cd(II) Coordination Polymers Induced by Bis(pyridyl) Ligand with Chelated or Protonated Spacer and Diverse Counteranions Cryst. Growth Des. 172667

12. Duan X Y and Wei M L 2017 From One-Dimensional, Two-Dimensional to Three-Dimensional Entangled Architectures with Polythreading Feature: Synthesis, Structures, and Properties Cryst. Growth Des. 171197

13. Hao S Y, Hou S X, Hecke K V and Cui G H 2017 Construction of noninterpenetrating and interpenetrating $\mathrm{Co}(\mathrm{II})$ networks with halogenated carboxylate modulated by auxiliary $\mathrm{N}$-donor co-ligands: structural diversity, electrochemical and photocatalytic properties Dalton Trans. 461951

14. Zhang J W, Kan X M, Li X L, Luan J and Wang X L 2015 Transition metal carboxylate coordination polymers with amide-bridged polypyridine co-ligands: assemblies and properties CrystEngComm 173887

15. Liu P P, Cheng A L, Yue Q, Liu N, Sun W W and Gao E Q 2008 Cobalt(II) Coordination Networks Dependent upon the Spacer Length of Flexible Bis(tetrazole) Ligands Cryst. Growth Des. 81668

16. Lee $\mathrm{S}$ Y, Park S, Kim H J, Jung J H and Lee S S 2008 Ligand- and Anion-Directed Assembly of ExoCoordinated Mercury(II) Halide Complexes with $\mathrm{O}_{2} \mathrm{~S}_{2}$ Donor Macrocycles Inorg. Chem. 471913

17. Cheng P C, Kuo P T, Liao Y H, Xie M Y, Hsu W and Chen J D 2013 Ligand-Isomerism Controlled Structural Diversity of $\mathrm{Zn}(\mathrm{II})$ and $\mathrm{Cd}(\mathrm{II})$ Coordination Polymers from Mixed Dipyridyladipoamide and Benzenedicarboxylate Ligands Cryst. Growth Des. 13623

18. Cheng J J, Chang Y T, Wu C J, Hsu Y F, Lin C H, Proserpio D M and Chen J D 2012 Highly interpenetrated 
diamondoid nets of $\mathrm{Zn}$ (II) and $\mathrm{Cd}(\mathrm{II})$ coordination networks from mixed ligands CrystEngComm 14537

19. Gong $\mathrm{Y}, \mathrm{Li} \mathrm{J}$, Qin $\mathrm{J} \mathrm{B}, \mathrm{Wu} \mathrm{T}$, Cao R and $\mathrm{Li} \mathrm{J} \mathrm{H}$ 2011 Metal(II) Coordination Polymers Derived from Bis-pyridyl-bis-amide Ligands and Carboxylates: Syntheses, Topological Structures, and Photoluminescence Properties Cryst. Growth Des. 111662

20. Wang X L, Luan J, Sui F F, Lin H Y, Liu G C and Xu C 2013 Structural Diversities and Fluorescent and Photocatalytic Properties of a Series of $\mathrm{Cu}^{\mathrm{II}}$ Coordination Polymers Constructed from Flexible Bis-pyridylbis-amide Ligands with Different Spacer Lengths and Different Aromatic Carboxylates Cryst. Growth Des. 13 3561

21. Wang X L, Sui F F, Lin H Y, Zhang J W and Liu G C 2014 Multifunctional Cobalt(II) Coordination Polymers Tuned by Flexible Bis(pyridylamide) Ligands with Different Spacers and Polycarboxylates Cryst. Growth Des. 143438

22. Wang X L, Luan J, Lin H Y, Lu Q L, Xu C and Liu G C 2013 Effect of flexible bis-pyridyl-bis-amide ligands and dicarboxylates on the assembly and properties of multifunctional $\mathrm{Cu}$ (II) metal-organic coordination polymers Dalton Trans. 428375

23. Wang X L, Luan J, Lin H Y, Liu G C and Le M 2014 Four cobalt(II) coordination polymers based on a flexible N,N'-bis(3-pyridinecarboxamide)-1,6-hexane ligand: Modulation of crystal architectures through the substituent groups of isophthalates Polyhedron 711111

24. Cheng P C, Kuo P T, Xie M Y, Hsu W and Chen J D 2013 Structure-directing roles of auxiliary polycarboxylate ligands in the formation of $\mathrm{Zn}$ (II) and $\mathrm{Cd}(\mathrm{II})$ coordination polymers based on a flexible $N, N^{\prime}-\operatorname{di}(3-$ pyridyl)dodecanediamide CrystEngComm 156264
25. Lin H Y, Lu H Z, Le M, Luan J, Wang X L and Liu G C 2015 Three 2 D copper(II)/cadmium(II) coordination polymers based on semi-rigid/flexible bis-pyridylbis-amide ligands and 5-aminoisophthalate: Syntheses, structures and properties J. Chem. Sci. 1271275

26. Lu Q L, Luan J, Wang X L, Lin H Y, Le M and Liu G C 2014 Molecular structure and nitrite-bonded study on copper(II) complexes of $\mathrm{N}, \mathrm{N}$-dialkyl, $\mathrm{N}^{\prime}$-benzylethylenediamine; synthesis, spectroscopic characterization, X-ray structure, steric effect and density functional theory calculations Polyhedron $\mathbf{8 3} 108$

27. Lin H Y, Rong X, Liu G C, Wang X, Wang X L and Duan S R 2016 Fluorescent sensing and electrocatalytic properties of three $\mathrm{Zn}(\mathrm{II}) / \mathrm{Co}(\mathrm{II})$ coordination complexes containing two different dicarboxylates and two various bis(pyridyl)-bis(amide) ligands J. Mol. Struct. 1119396

28. Muthu S, Yip J K and Vittal J J 2002 Coordination networks of $\mathrm{Ag}(\mathrm{I})$ and $N, N^{\prime}$ - bis(3-pyridinecarboxamide)1,6-hexane: structures and anion exchange J. Chem. Soc. Dalton Trans. 4561

29. Sarkar M and Biradha K 2006 Amide-to-Amide Hydrogen Bonds in the Presence of a Pyridine Functionality: Crystal Structures of Bis(pyridinecarboxamido)alkanes Cryst. Growth. Des. 6202

30. Sheldrick G M 2008 A short history of SHELX Acta Crystallogr. A 64112

31. Cui Y J, Yue Y F, Qian G D and Chen B L 2012 Luminescent Functional Metal-Organic Frameworks Chem. Rev. 1121126

32. Sun G M, Huang H X, Tian X Z, Song Y M, Zhu Y, Yuan Z J, Xu W Y, Luo M B, Liu S J, Feng X F and Luo F 2012 Carboxylate-assisted acylamide metal-organic frameworks: synthesis, structure, thermostability and luminescence studies CrystEngComm 146182 